\title{
Provinha Brasil: reflexões sobre cotidiano escolar e formação de professores
}

\author{
Ana Lúcia T. Schilke *, Fabiana Eckhardt** \\ * UFF/ FME - Brasil, ** UFF/UCP- Brasil
}

\begin{abstract}
Resumo
O presente estudo objetiva discutir a relação entre avaliação externa e cotidiano escolar. Tal trabalho justifica-se, na medida em que as avaliações externas estão cada dia mais presentes na escola, refletindo o que vem sendo preconizado em diversos estados/países, inclusive Brasil. No referido trabalho, tomamos como estratégia metodológica a aplicação de um questionário semiestruturado sobre a Provinha Brasil, destinado a professores dos anos iniciais de uma rede municipal e a estudantes do curso de pedagogia de uma instituição privada. É possível inferir que tais exames associados a políticas de formação reduzem a compreensão do professor sobre a aprendizagem e ensino.

Palavras-chave: Provinha Brasil, formação de professores , cotidiano escolar
\end{abstract}

"Em resumo, não se pode observar uma onda sem ter em conta os aspectos complexos que concorrem para a sua formação e aqueles outros, igualmente complexos, a que essa mesma onda dá lugar"

Ítalo Calvino, in Palomar

O texto de Calvino nos serve de metáfora para pensar sobre os impactos das avaliações externas no cotidiano escolar, visto que esses exames vêm ocupando, como uma onda, a centralidade das políticas educacionais em diversos países, inclusive no Brasil.

Longe de ser uma unanimidade, a avaliação da educação básica no Brasil é campo de disputas teóricas e metodológicas, tendo como uma de suas questões nevrálgicas os exames externos, pautados no rendimento do estudante e que são traduzidos em índices que quantificam e qualificam tal desempenho.

Para Esteban (2012), a onda das avaliações externas tem dado lugar à destruição das multiplicidades pedagógicas presentes no espaço escolar, à universalidade de práticas e à redução das propostas curriculares. Nesse sentido, o presente trabalho objetiva refletir, a partir de informações coletadas em um questionário semiestruturado sobre a Provinha Brasil, possíveis impactos das avaliações externas no cotidiano escolar e na formação de professores e, como tais impactos fortalecem as relações de colonialidade.

\section{A onda das avaliações externas no Brasil}

As avaliações externas vêm ocupando a centralidade das políticas educacionais em diversos países, inclusive no Brasil. Observamos em estados e municípios, com maior ou menor intensidade, políticas educacionais que focalizam seus investimentos, prioritariamente, em políticas de avaliação meritocrática, materializadas em exames externos de larga escala. Padronizadas, aplicadas, em determinados momentos, por avaliadores externos com o objetivo de monitorar o desempenho dos estudantes, querem essas avaliações corrigir possíveis insuficiências e, no limite, estabelecer novos parâmetros de gestão dos sistemas educacionais. Nesta lógica, avaliar é olhar de fora, em um determinado momento. É valorizar um único conhecimento e apagar todo o percurso e a realidade à qual a instituição escolar se encontra circunscrita.

Para Assis e Amaral (2013), no Brasil, inúmeros estudos afirmam que nas últimas duas décadas, as avaliações externas não lograram êxito, apesar de seu propósito indutor de qualidade de ensino. Ou seja, passados mais de 20 anos da adoção de políticas avaliativas externas, aplicadas em diversos níveis de ensino, a qualidade da educação não sofreu mudanças significativas em relação à democratização do acesso ao conhecimento, pois um número expressivo de pessoas são consideradas analfabetas, segundo dados do $\mathrm{IBGE}^{1}$ 2010 .

De acordo Fernandes (2009), os exames externos são organizados a partir de um currículo único, estandartizados e exercem função de certificar, controlar e selecionar. Esse conjunto de intenções está alinhado a processos de regulação, prestação de contas e responsabilização, fazendo com que a avaliação deixe de ser um processo construído coletivamente de tomada de decisão, para se tornar apenas instrumento de medida de eficiência, desresponsabilizando o Estado que restringe a sua atuação a um caráter avaliador/regulador. (FREITAS, 2007; ASSIS e AMARAL, 2013)

Segundo Ronca (2013), a sistemática da avaliação externa na Educação Básica teve grande impulso em 1988, quando os exames começaram a surgir, ainda que de forma amostral. No ano de 2005, foi instituído o Sistema de Educação Básica (SAEB), conforme portaria $n^{\circ} 931 / 2005$, passando para um sistema de avaliação de larga escala, universal, padronizado e bianual. Os resultados são amplamente divulgados e introduzem a responsabilização e a suposta mobilização social a favor da escola pública. Com o fluxo de estudantes e o desempenho destes no exame, formula-se o Índice de Desenvolvimento da Educação Básica (IDEB), que almeja explicar aspectos da realidade, permitir o monitoramento e exercer "função de síntese, objetivando, desta maneira, ajudar o poder público a tomar decisões referente às políticas públicas" [...] "Além de articular os conceitos de fluxo e desempenho, o IDEB fornece informações importantes para escolas e

\footnotetext{
${ }^{1}$ Segundo dados do IBGE, aproximadamente 18 milhões de brasileiros não sabem ler e escrever - dados coletados em 20/06/2015 em: http://7a12.ibge.gov.br/pt/vamos-conhecer-o-brasil/nosso-povo/educa cao
} 
sistemas, por revelar práticas e, também, apontar aquelas escolas ou redes que estão com dificuldades e precisam receber apoio técnico". (RONCA, 2013, p.78).

Ao apontar a possibilidade de revelar práticas e escolas ou redes que estão com dificuldades, o SAEB visibiliza diferenças dentro do próprio sistema educacional. Analisadas pela perspectiva do desempenho, proporciona juízo de valor que acaba por hierarquizar saberes e fazeres, criando um julgamento redutor do processo educacional ao possibilitar a classificação entre escolas ditas boas e ruins, a partir do IDEB.

Atualmente o $\mathrm{SAEB}^{2}$ assume maior abrangência, envolvendo a Avaliação Nacional da Educação Básica (Aneb), a Avaliação Nacional do Rendimento Escolar (Anresc - também denominada "Prova Brasil") destinada aos alunos da $4^{\mathrm{a}}$ série $/ 5^{\circ}$ ano e $8^{\mathrm{a}}$ série $/ 9$ ano e a Avaliação Nacional da Alfabetização (ANA), destinadas aos alunos do $2^{\mathrm{a}}$ série $/ 3^{\circ}$ ano, ambas aplicadas na rede pública com caráter censitário.

Associado a este conjunto de avaliações, o Brasil ainda conta com a Provinha Brasil ${ }^{3}$, foco deste trabalho, que tem por objetivo a avaliação diagnóstica do nível de alfabetização de crianças com, aproximadamente, 7 anos, matriculadas no $2^{\circ}$ ano de escolaridade.

Sua aplicação se dá, a partir de 2008, e avalia as habilidades da leitura e escrita, e, em 2011, incorpora também as habilidades matemáticas. Sua ocorrência é censitária, em duas etapas, sendo a primeira em abril e a segunda em outubro, sob o argumento de permitir mais informações aos professores e gestores auxiliando no monitoramento e na avaliação dos processos de desenvolvimento da alfabetização e do letramento inicial e das habilidades iniciais em matemática, oferecidos nas escolas públicas brasileiras, mais especificamente, a aquisição de habilidades de Leitura e de Matemática.

O referido estudo toma a Provinha Brasil como foco de investigação por ser a avaliação externa aplicada aos alunos mais novos e por estar vinculada a um conjunto de ações instituídas após o Plano de Metas Compromisso Todos pela Educação e o Pacto Nacional pela Alfabetização na Idade Certa - PNAIC. Para tanto, envolve uma série de estratégias que abrange a avaliação de desempenho e a formação de professores, o que pode impactar no cotidiano escolar e nas formações iniciais e em serviço ${ }^{4}$.

Juntamente com a ANA, a Provinha Brasil integra um dos 4 eixos estruturantes do PNAIC, que envolvem formação continuada presencial, material didático,

\footnotetext{
${ }^{2}$ Informações coletadas em 13/06/2015 em

http://portal.inep.gov.br/web/saeb/aneb-e-anresc

3 Informações coletadas em 13/06/2015 em

http://portal.inep.gov.br/web/provinha-brasil

${ }^{4}$ Entendemos o Pacto como estratégia de formação continuada. A formação que ocorre no cotidiano escolar, fruto da conquista do um terço de planejamento, assumimos como formação em serviço. Já a formação inicial, é aquela realizada por instituições autorizadas que certificam o profissional de educação.
}

avaliações sistemáticas e modelo de gestão. $\mathrm{O}$ alcance nacional do PNAIC só é possível devido a parcerias estabelecidas entre Governo Federal, Estados e Municípios e 39 universidades espalhadas pelo Brasil.

A provinha Brasil é um dos investimentos feitos pelo governo federal, que têm por objetivo garantir a alfabetização de todos os alunos aos 8 anos, considerada a "idade certa". São iniciativas governamentais, efetivadas em parcerias com centros formadores que pretendem capacitar mais de 360 mil professores alfabetizadores até 2015 e alfabetizar plenamente 100\% dos alunos, ao final dos 3 anos iniciais da escolarização em língua portuguesa e matemática.

A formação é realizada em encontros presenciais entre os professores alfabetizadores e os orientadores de estudo, com carga horária de 120 horas por ano com duração de 2 anos. Os orientadores, professores também da rede, participam de formação ofertada pelas instituições superiores de ensino parceiras, com carga-horária de 200 horas, com o referencial teórico do Programa Pró-letramento. Ou seja, em um movimento em cascata, os centros formadores passam para os orientadores o debate a ser desenvolvido na lógica do Pró-letramento, e estes passam para os professores alfabetizadores. Associada à formação, os professores recebem material didático específico e, seus alunos devem ser submetidos à Provinha Brasil, em duas etapas durante o ano.

É um exame de caráter diagnóstico que intenciona ser utilizado como instrumento de estudo e desenvolvimento de ações preventivas para minorar os efeitos do fracasso escolar. Por ser um instrumento que se alia aos demais exames de larga escala, formulados externamente, não dialoga com a sala de aula, gerando significativa tensão entre o que é preconizado pelos documentos oficiais e o que ocorre no cotidiano escolar, seja antes, durante ou após a sua aplicação.

Mesmo não fazendo parte do IDEB, estudos conduzidos por Wolf (2015), indicam que a Provinha Brasil vem ganhando novas configurações que apontam "para a possibilidade de utilização de uma plataforma nacional de resultados, o que pode indicar que o interesse em visualizar como se comporta a produção dos resultados da Provinha, começa oficialmente ir além da proposta de subsidiar internamente as escolas e redes Municipais de Ensino".

Assim, uma avaliação que se inicia com uma forma de diagnose começa a assumir características que a colocam dentre as ações de controle e regulação do Estado e não de uma ferramenta de apoio pedagógico.

$\mathrm{Na}$ revisão de literatura ${ }^{5}$ realizada, encontramos 8 trabalhos que tomam como objeto de estudo a Provinha Brasil. Tais trabalhos, majoritariamente, debatem o tema a partir das políticas públicas e curriculares. Como nosso foco de estudo centra-se na relação da Provinha Brasil com o cotidiano escolar e a formação docente inicial e

\footnotetext{
${ }^{5}$ A referida revisão foi realizada em 20/06/2015 na base da SCIELO. Utilizamos como palavras-chave: provinha Brasil, e posteriormente provinha Brasil associada a cotidiano escolar, formação de professores, formação docente, formação em serviço e formação continuada.
} 
em serviço, também trabalhamos na referida revisão, associando as palavras-chave Provinha Brasil à formação de professores, à formação continuada, à formação inicial e à formação em serviço. Neste levantamento não identificamos nenhum trabalho que toma como objeto de estudo a formação de professores em nenhum de seus níveis. Já em relação a cotidiano escolar, identificamos apenas 1 trabalho.

Devido ao número reduzido de pesquisas, é possível inferir a necessidade de estudos que se debrucem sobre a Provinha Brasil . Para além de investigar as políticas públicas e o currículo, é premente que se realizem estudos sobre os possíveis impactos sobre o cotidiano escolar e a formação de professores.

\section{A Provinha Brasil no cotidiano escolar e na formação de professores: reflexões sobre o fortalecimento das relações de colonialidade.}

Tendo como pano de fundo as considerações aventadas anteriormente, a investigação realizada traz reflexões sobre a formação de professores, o cotidiano escolar e os estudos pós-coloniais. Optamos por este caminho, pois, em nossos espaços de pesquisa, identificamos nos discursos das professoras ${ }^{6}$ e estudantes do curso de pedagogia, sujeitos de nossos estudos, discursos e interpretações disformes em relação aos exames externos. Preocupadas com os possíveis impactos desta lógica de avaliação e a relação com as questões da colonialidade, propomo-nos a investigar três indagações. Quais os conhecimentos sobre a Provinha Brasil, professores e estudantes, do nosso espaço de pesquisa, sinalizam em seus discursos? Quais os possíveis impactos desse exame em seus cotidianos? Como tais impactos podem reforçar as relações de colonialidade?

$\mathrm{O}$ instrumento privilegiado para a tessitura deste texto foi um questionário semiestruturado que versou sobre a Provinha Brasil. Tal estratégia foi adotada com os seguintes objetivos: recolher informações sobre como esses estudantes e professoras incorporam esse instrumento avaliativo; identificar o que circula em seus espaços de formação de professores, inicial e em serviço, em relação à Provinha Brasil; cotejar as possíveis mplicações percebidas por esse grupo em seus cotidianos.

Tivemos, como procedimento metodológico, a tabulação das questões objetivas e a leitura em profundidade das questões discursivas. A referida leitura possibilitou elencar questões a partir de pistas, sinais e indícios (GINZBURG, 1989) que foram revelados nos discursos dos estudantes $\mathrm{e}$ das professoras. A fundamentação teórica pautou-se nos estudos pós-colonial conduzidos por Dussel (2000), Quijano (2005), e Santos (2010) e sobre avaliação educacional realizado por Esteban (2012).

Trabalhamos com dois grupos distintos, totalizando 40 participantes, 20 estudantes formandos e 20 professoras atuantes nos anos iniciais do Ensino Fundamental. Dos

\footnotetext{
${ }^{6}$ Optamos por utilizar neste texto o substantivo no feminino por tratar-se de um estudo que contou somente com a participação de professoras mulheres
}

estudantes do curso de Pedagogia que responderam ao questionário, todos tinham conhecimento da Provinha Brasil, embora somente três deles tivessem contato com o referido exame. O mesmo aconteceu com as professoras, todas conheciam a Provinha Brasil, mas nesse caso, somente três não tiveram contato direto com ela.

Alicerçadas nas respostas, é possível inferir que ambos os grupos tinham conhecimento sobre a Provinha Brasil como um exame de larga escala. Acreditamos que tal informação se dê, por um lado, pelo amplo espaço de divulgação que as provas de larga escala têm alcançado nas mídias em geral e no debate educacional. Por outro lado, percebemos respostas variadas quanto ao momento da aplicação, ao ano a que se destina e ao propósito do exame. A diversidade de respostas nos levou a inferir que o conhecimento sobre os diversos exames externos se entrelaçam. Para nós, os discursos das professoras e dos estudantes sinalizam desconhecimento sobre os meios e os fins de cada exame específico que compõem o SAEB. Os estudantes $\mathrm{e}$ as professoras sabem da existência das avaliações, mas parecem não entender a especificidade de cada uma nas diversas etapas que estruturam o sistema nacional de avaliação.

O grupo de estudantes, de uma maneira geral, apresentou discurso mais crítico em relação ao exame, pois problematizou a concepção de avaliação trazida pela provinha. Em suas falas destacaram a Provinha Brasil como: "um meio de avaliação falho, pois os resultados obtidos não são capazes de avaliar todo o processo de aprendizagem do sujeito." ou ainda "não deveria existir, não avalia o aprendizado, apenas força escola, professores e alunos a terem eficiência no momento da aplicação da prova."

Concordando com os estudantes, mas em número menor, as professoras também se posicionaram contrárias ao exame, conforme pode ser observado numa das falas das professoras, "não condiz com a realidade do conteúdo que se cobra em sala".

Ambos os grupos demonstraram perceber influências do exame no cotidiano da escola. "Os professores aplicam atividades voltadas para o exame", "os professores passam os conteúdos da prova". Esses sujeitos reconhecem certa preparação para a realização do exame, "pois é necessário apresentar aos alunos a ideia de marcar uma questão" e "o professor passa a tensão para os alunos, treinando-os".

Tais falas levam-nos a constatar que o exame em questão interfere nos conteúdos e nas ações cotidianas ao induzir práticas que reduzem o potencial criativo e autônomo de estudantes e professoras. Reduz, na mesma medida, a maneira como são vistas as crianças e as professoras.

Em relação à criança, o exame adota um único caminho pedagógico, o pró-letramento, que exclui outras metodologias pedagógicas ao não favorecer as diferentes formas que cada estudante apresenta em seu processo singular de aquisição da língua escrita. Assim, os estudantes que não seguem o mesmo caminho são considerados "com dificuldades", e a diferença passa a justificar a exclusão no processo educacional, tornando diferença sinônimo de desigualdade (ESTEBAN, 2012). 
Já as professoras, pela inserção do exame e pela formação do PNAIC, são desapropriadas de seu lugar de docente, pois há o controle de suas práticas, em forma e conteúdo, sendo colocadas num lugar de dependência e submissão (ESTEBAN, 2012). Formação e ação docente assumem o conhecimento eurocêntrico (QUIJANO, 2005) como referência, e as práticas pedagógicas (avaliativas ou não) são conduzidas de forma a buscar a homogeneidade do conhecimento. Assim, invisibilizam os avanços que as crianças vão tendo, se forem apresentados de maneira distinta do padrão prescrito. Formatam o trabalho do professor, reforçando processos de subalternização, silenciando saberes, culturas e pessoas. (DUSSEL, 2000)

As avaliações de larga escala, e nesse caso, a Provinha Brasil e o PNAIC, propõem a garantia de qualidade pela eficiência no controle de resultados. Modelam a gestão educacional e as práticas docentes em busca do aumento de índice de desempenho. No entanto, o que vemos é o reforço das relações de colonialidade na escola, camufladas pela promessa de garantir o direito à educação a todos sem distinção. Compromete todos os sujeitos presentes no cotidiano escolar em um pacto em busca da qualidade. Fica evidenciada, portanto, a promoção de práticas que se fundamentam em concepções tecnicistas que levam a uma qualidade reduzida, pois não garantem a aprendizagem de todos.

Ao classificar e hierarquizar os resultados nas avaliações e ao reforçar práticas instrumentais, essa política consolida e alimenta as desigualdades no cotidiano escolar. Os saberes presentes nesse espaço, trazidos por estudantes e professores, que não dialogam com a lógica dos exames, vão sendo subalternizados e apresentados como os saberes do outro, o ilegítimo. O outro é aquele que não se encaixa dentro dos padrões estabelecidos pelos exames, sendo necessário ocultar sua identidade cultural preexistente. $\mathrm{O}$ outro inquieta a segurança de saberes e práticas hegemônicas, assim, na lógica colonial, devem ser invisibilizados os seus modos de ser e de saber, desconsiderados de forma a apagar suas crenças, valores, saberes e fazeres.

Com o discurso do direito à educação para todos, a Provinha Brasil pode ser entendida como uma estratégia politicamente democrática, mas socialmente desigual, por ser um exame que realça "relações de poder extremamente desiguais, pois concedem a parte mais forte o poder de veto sobre a vida e modo de vida da parte mais fraca" (SANTOS, 2010). Uma forma de colonialidade, pois é uma dominação não só política, mas também epistemológica, pautada em relações desiguais entre os saberes, que naturaliza um único modo de saber, de ser e de estar no mundo. Coloca os saberes próprios dos sujeitos colonizados num espaço de subalternidade ao controlar subjetividades, cultura, e em especial, o conhecimento e a produção de conhecimento (QUIJANO, 2005).

Ao olhar os discursos dos estudantes e das professoras, buscando pistas, sinais, indícios sobre os possíveis impactos da Provinha Brasil, identificamos elementos que denunciam a colonialidade do ser e do saber.

Em síntese, o estudo nos mostrou que estudantes e professoras, sujeitos dessa investigação, possuem um breve conhecimento do exame em questão. Apesar de apresentarem críticas ao instrumento como proposta de avaliação, bem como o direcionamento das práticas e dos conteúdos, parecem não reconhecer todos os aspectos do PNAIC dentro do sistema de avaliação nacional. Não reconhecem como a formação do PNAIC permeia o cotidiano, condicionando práticas. A crítica esgota-se na Provinha Brasil, pois a formação ofertada é vista como um ganho, como se fosse desarticulada do exame. Ou seja, em seus discursos, a formação e a Provinha Brasil não são reconhecidas como elementos indissociáveis ao Pacto Nacional pela Alfabetização na Idade Certa.

Utiliza-se o exame ancorado em provas estandartizadas que valorizam a homogeneidade de processos, percursos e resultados com intuito de aferir qualidade. Não é apenas um exame externo que, à distância, pode direcionar a ação pedagógica. O que observamos, nos documentos oficiais produzidos e na incorporação no cotidiano escolar dos sujeitos de nossas pesquisas, é um conjunto de ações em que estudantes e professoras são subalternizados numa relação de colonialidade.

Nesse sentido, vemos de um lado, as professoras assumindo e executando o pacto, do outro, os espaços de formação de professores (inicial e em serviço) alijados da sua função formadora. São instituições fundantes historicamente na formação de professores, mas que no pacto são desconsideradas. O que fica como questão para tais instituições é: - Qual o seu papel na formação de professores neste cenário?

$\mathrm{O}$ que cabe às instituições formadoras, parece-nos que é ir além da crítica, ou seja, entrar na disputa do espaço que está sendo tomado. De acordo com os estudos acerca das avaliações de larga escala, nesse caso, a Provinha Brasil, a crítica já está posta. Ficamos com o legado de colocarmo-nos frontalmente contra tais práticas, e pensar estratégias pedagógicas para e na formação de professores que rompam com a fragmentação do conhecimento que inferiorizam sujeitos e saberes ao negar valor à diferença.

\section{Referências}

Assis, L.M. \& Amaral, N.C. (2013). Avaliação da educação - Por um sistema nacional. Retratos da Escolal Escola de Formação da Conferência nacional dos Trabalhados em Educação (Esforce), $N^{\circ} .12$ Vol7, 27-47.

Dussel, E. (2000). Ética da Libertação: na idade da globalização e da exclusão. Petrópolis: Vozes.

Esteban, T. (2012). Considerações sobre a política de avaliação da alfabetização: pensando a partir do cotidiano escolar. Revista Brasileira de Educação. $N^{o}$ 51 Vol 17, p.573-592.

Fernandes, D. (2009). Avaliar para aprender: Fundamentos, práticas e políticas. São Paulo: Unesp.

Freitas, L.C.de. Eliminação adiada: o ocaso das classes populares no interior da escola e a ocultação da (má) qualidade do Ensino. Educação e Sociedade. $N^{o} 100$ Vol 28, p.965-987.

Ginzburg, C. (1989). Mitos, emblemas e sinais. São Paulo: Cia das Letras. 
Quijano, A. (2005). Colonialidade do poder, eurocentrismo e América Latina. En LANDER.E. (Org). A colonialidade do saber: eurocentrismo $e$ ciências sociais. Perspectivas latino-americanas. (pp.227-278)

Ronca, A.(2013). Avaliação da educação básica- Seus limites e possibilidades. Retratos da Escola 77-85.

Santos, B.S. (2009). Para além do pensamento abissal: das linhas globais a uma ecologia de saberes. En:
Santos, B.S.; Menezes, M.P. (Org.). Epistemologias do Sul (pp. 23-71).

Wolf, C.C. (2015) Provinha Brasil no municipio de Niterói: uma discussão sobre avaliação e concepções de aprendizagem na alfabetização (Monografia de Especialização em Alfabetização de Crianças de Classes Populares) Universidade Federal Fluminense, Niterói. 